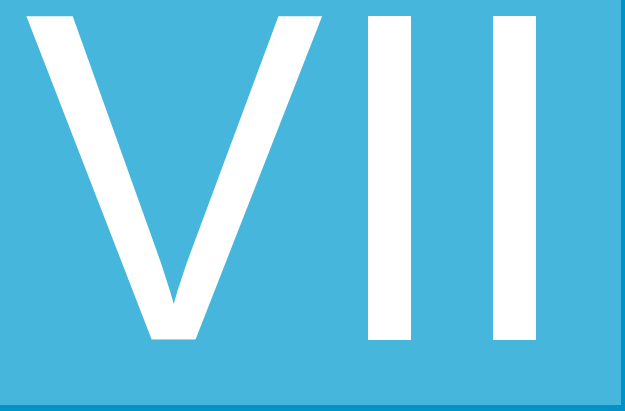

\title{
DEL DESCRIPTOR AL PRESCRIPTOR: ESCRITURA, TEOLOGÍA Y PRAXIS EN UN MUNDO SUMERGENTE
}

\author{
Descriptor to prescriber: Scripture, Theology and Praxis in a \\ world submergent \\ Universidad Adventista del Plata
}

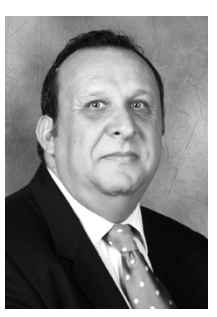

\section{Víctor M. Armenteros Cruz}

Licenciado en Teología por el Colegio Adventista del Plata (Argentina) y licenciado en Filología Semítica, con especialidad en hebreo y arameo, por la Universidad Central de Barcelona (España). Hizo cursos doctorales en Lengua y Cultura Hebraico-Española, con especialidad en Literatura Rabínica Tannaitica, por la Universidad de Granada (España). Doctor en Filología Semítica por la Universidad de Granada. Traductor del proyecto de la Biblia Interconfesional de las Sociedades Bíblicas y la Casa de la Biblia. Escritor prolífico y ponente internacional. Actualmente se desempeña como Vicerrector Académico de la Universidad Adventista del Plata. 


\section{Resumen}

El objetivo de este estudio se enmarca en estas demandas con el afán de aproximarse a la mirada del escritor bíblico y además, anhelo atrevido, entrever la del mismísimo Yhwh. Se concluye que una disponibilidad de la Biblia presente entre los creyentes y, a su vez, alejada de los intereses del mercado es necesaria. Versiones del texto que establezcan, además de contextualización, relaciones con la verdad del contenido y con las necesidades de los receptores. Una vuelta al canon primigenio por la falta de un modelo original. Una hermenéutica histórico-lingüística que sea prescriptiva y sentimental, la emoción discurriendo a través de la razón.

Palabras clave: Registro bíblico, hermenéutica, traducción, interpretación.

\section{Abstract}

The objective of this study is part of these demands in an effort to approximate the look of the biblical writer and also longing daring glimpse of the Yhwh himself. We conclude that availability of the Bible present among believers and turn away from the interests of the market is necessary. Versions of the text to establish further contextualization, relations with the truth of the content and the needs of the recipients. A return to primitive canon because the lack of an original model. A historical-linguistic hermeneutics that is prescriptive and sentimental, emotion running through reason.

Keywords: Bible record, hermeneutics, translation, interpretation 


\section{Introducción}

Es indudable que la visión que el registro bíblico presenta de la realidad no siempre es coincidente con las valoraciones de las sociedades de su entorno. Lo que, en ciertas ocasiones, es considerado como decadente y poco modélico en la Biblia se contrasta con las evaluaciones positivas y respetuosas de los coetáneos. Como muestra, un botón. Por un lado, "y Omrí hizo lo malo ante los ojos de Yhwh, e hizo peor que todos los que habían reinado antes de él; pues anduvo en todos los caminos de Jeroboam hijo de Nabat, y en el pecado con el cual hizo pecar a Israel, provocando a ira a Yhwh Dios de Israel con sus ídolos (1R 16,25-26)"; por otro lado, "Omrí fue el rey de Israel, y él oprimió Moab durante muchos días, pues Quemos estaba enfadado con su tierra (Estela de Mesa, líneas 4-6)".

Los omridas van a representar durante décadas a la Casa de Israel ante sus aliados y enemigos con la connotación de gobiernos de éxito comercial y armamentísticamente. Sus ejercicios de diplomacia se hallan entre los más destacados de su época. Como indica Grabbe (2007, pp. 4) comentando a Liverani:

The main contribution of Omri was the new capital at Samaria which was not just a simple royal residence but a true administrative centre of the kingdom. Under Omri and Ahab Israel experienced a notable growth in economics and culture... After the Israel of the house of Omri - censured for Baal worship by the prophets and later historiographers but politically strong and culturally flourishing - came the house of Jehu - lauded as Yahwistic but politically subordinate and territorially reduced to a minimum experienced a notable growth in economics and culture.

Y, sin embargo, a los ojos del escritor bíblico e, incluso, a los ojos del mismísimo Yhwh, no existe valoración positiva.

Tal conceptualización de la realidad, si se considera el material bíblico como generador de cosmovisiones, nos viene, ya desde siglos, obligando a reflexionar sobre las comprensiones al uso frente a las impregnadas por la visión bíblica. Nos impele a continuar preguntándonos con honestidad: ¿qué percepción de la realidad incorporo a mi vida como creyente, intelectual y religioso? ¿Qué aproximación realizo a la Escritura, la Teología y la praxis eclesiástica? ¿Hasta dónde mi posición ante el texto afecta cada una de estas dimensiones? 
El objetivo de este estudio se enmarca en estas demandas con el afán de aproximarse a la mirada del escritor bíblico y además, anhelo atrevido, entrever la del mismísimo Yhwh.

\section{Puntos de inflexión en sociedades sumergentes}

A posteriori, las cosas se contemplan diferentes. ¿Percibió Platón el alcance de sus reflexiones? ¿Intuyó Leonardo da Vinci las implicaciones de sus obras? ¿Fue consciente Kafka del impacto de sus idas y venidas? Posiblemente, algo. Hay certeza de que no tuvieron la mirada de lo retrospectivo pero captaron una porción de ese momento de cambio que estaban generando. $Y$ es que las variaciones de paradigmas se hacen notar desde la inseguridad de los pusilánimes hasta la apertura de los osados.

Hoy, vivimos tiempos de cambio y, curiosamente, podemos interpretarlos mejor mirando hacia otros puntos de inflexión para captar, desde sus variaciones de paradigmas, las intuiciones de las nuestras. Cuánto más en una sociedad sumergente como la nuestra. Y entiendo por "sumergente" aquella estructura social en la que los valores son sustituidos por elementos ajenos al sentido de las personas, elementos que generan disonancias en el desarrollo de la plenitud del ser humano. Como dirá Zizek $(2011$, p. 7):

En los tiempos que corren, las cosas no pintan bien para las grandes Causas, en una época en la que, aunque la escena ideológica está fragmentada en una panoplia de posiciones que luchan por la hegemonía, hay un concepto subyacente: la época de las grandes explicaciones ha terminado, necesitamos un "pensamiento débil", opuesto a todo fundacionalismo, un pensamiento atento a la estructura rizomática de la realidad; tampoco en el ámbito de la política debemos aspirar ya a sistemas que lo expliquen todo y a proyectos de emancipación mundial; la imposición violenta de grandes soluciones debe dar paso a formas de intervención y resistencias específicas...

\section{Lutero y la Baja Edad Media}

No hay imprecisión alguna al afirmar que la Europa de finales del siglo $\mathrm{XV}$ era un mundo sumergente. La analfabetización generalizada, la reducción de la sociedad en castas, el monopolio de la riqueza, la cultura y la religión transformaron los países en una amalgama de guerras, movimientos místicos y polarizantes, un espacio de sumisión de lo terreno y lo extraterreno. El mundo académico había alejado el mensaje del texto bíblico de la mayoría de la población y se fundamentaba en filosofías grecolatinas. 
La relación de aquella sociedad con la Biblia establecía con claridad el diagnóstico de estructura sumergente. La disponibilidad de ejemplares para leer o estudiar era escasa. La Biblia era un texto minoritario y de difícil acceso. Oscurecida por la Escolástica y el Magisterio de la Iglesia católica, la lectura de los materiales bíblicos era ajena a la realidad de la mayoría de los cristianos. Apenas los autos sacramentales transmitían a los pueblos el mensaje mismo del Evangelio.

La variedad de textos se restringe al latín, lengua ajena a la comunicación usual de las naciones de los imperios cristianos de occidente. La Vulgata se globaliza, aunque con variantes e inclusiones de la Vetus Latina, en los diferentes territorios y, a su vez, se convierte en lengua sacra e incomprensible.

La configuración del canon, alejándose de la composición de la Tanak, se había ampliado a los libros deuterocanónicos (nomenclatura de Sixto de Siena). La inclusión de los textos de la LXX se realiza por intereses doctrinales y políticos (v.g.: la inclusión de la doctrina del purgatorio o de la imortalidad del alma). Con tal proceso se hibrida la cosmovisión hebrea con la griega (ejercicio de mezcla que venía instalándose desde el tiempo de Orígenes). La aproximación interpretativa, recordamos de nuevo a Orígenes, es alegórica. La señal y el signo eluden la aplicación concreta del mensaje bíblico. La alegoría, en su tangencialidad, genera en el receptor un entorno de ambigüedad que deriva en confusión. ${ }^{1}$

Se considera al texto bíblico como "Sagrada Escritura" y la adjetivación tiene una notable implicación en el concepto de relevancia. Es un material mágico que posee negatividad implícita. Es, por tanto, "sagrada" en la definición de Antúnez (2001, p. 196) refiriéndose a André Frossard:

En primer lugar hay que hacer una distinción entre lo sagrado y lo santo. Lo sagrado ha sido creado por el instinto humano para contener la violencia. Lo sagrado debe inspirar cierto terror, conteniendo y manteniendo a distancia. Hay ciertas cosas que no se deben tocar, sin decir el porqué. Si a uno le dieran una explicación, comenzaría una discusión filosófica y lo sagrado desaparecería.

\footnotetext{
${ }^{1}$ Véase Whitman, J. (2000). Interpretation and Allegory: Antiquity to the Modern Period. Leiden: Brill; Barnard, L. (1982). To Allegorize or not to Allegorize, Studia Theologica 36, 1, pp. 1-10; Bostock, G. (1987). Allegory and the Interpretation of the Bible in Origen, Literature and Theology 1, 1, pp. 39-53; Hanson, R. (1959). Allegory and Event: A Study of the Sources and Significance of Origen's Interpretation of Scripture Richmond: John Knox Pr; Newhauser, R., y Alford, J. (1995). Literature and Religion in the Later Middle Ages: Philological Studies in Honor of Siegfried Wenzel. Binghamton, NY: State University of New York; Aers, D. (1986). Medieval Literature: Criticism, Ideology and History. New York: St Martin's; Kannengiesser, Ch., y Petersen, W. (1988). Origen of Alexandria: his world and his legacy. Notre Dame, Ind: University of Notre Dame; Schwartz, R. (1990). The Book and the Text: The Bible and Literary Theory. Oxford: Basil Blackwell.
} 
El eje de acción se desarrolla en el mundo de la simbología, de los signos, de la reliquia, del misterio. La totemización de los instrumentos y su sacramentalización lleva al creyente a un mundo teocéntrico que es ajeno a su sentido de vida. El objeto (sea obra, mérito o indulgencia) adquiere un mayor significado que la persona que se halla alienada de sentido.

La autoridad de la Biblia se comparte con el Magisterio de la Iglesia lo que desdibuja su función principal de guía de valores. El hecho de que el magisterio pontifical se embargue de infalibilidad unido al cisma de occidente aportó mutabilidad por intereses políticos o, simplemente, económicos.

La traducción generalizada en espacio y tiempo al latín, liturgiza la Biblia limitándola a los momentos de ritos o de admoniciones. El impacto de frases hechas sin una comprensión completa del significado llegará hasta nuestros días. Expresiones como "vade retro", "inri", "ecce homo!", "vanitas vanitatum" aún adornan algunas de nuestras conversaciones.

Tanto la falta de disponibilidad como la escasa variedad de la Escritura, la ampliación por intereses políticos del canon, la alegoría que forja un pensamiento simbólico, una autoridad compartida con el valor del Magisterio eclesiástico o una traducción liturgizada generan en el hombre de la Edad Media tres valores claramente sumergentes: la fidelidad, la jerarquía y el honor. (Le Goff, 2008). La fidelidad que se asocia a las castas de la estructura feudal en la que la multitud de vasallos se atienen a los deseos de sus señores. Irregularidades que tendrían su concreción en prácticas como el "ius primae noctis" o derecho de pernada. La jerarquía que divide el mundo en bellatores (aristocracia militar que gobierna sus dominios), oratores (todos aquellos que se dedican a la oración y que tienen una notable influencia religiosa) y laboratores (usualmente campesinos que sostienen con su trabajo la sociedad). Le Goff (1985) sostendrá que esta estructura ternaria será el ambiente idóneo para que surja la teología del purgatorio. El honor se asociaba a la nobleza y recordaba constantemente la condición pecadora del pueblo llano. Como indica Carrasco (2008, p. 155):

Así, el punto de arranque radicaba en los motivos de la desigualdad jerárquica en la estructura social, y se planteó desde ópticas diversas. Una de ellas situaba la base de partida en una concepción según la cual, siendo todos nobles por voluntad divina -"Dios fizo omes e no fizo linajes. A todos fizo nobles en su nacimiento"- la pérdida de dicha condición había sido responsabilidad de los errores o pecados de los individuos; después, a lo largo del proceso histórico, en razón de su comportamiento -“a todos 
se dio elección de costumbres cuando viven"-, solo algunos habían sabido recuperar dicha condición, y mantenerla, transmitiéndola por la sangre.

El empleo inadecuado de la Escritura y de la Teología llevaron, en la praxis, a un mundo sumergente que se alejaba de los principios bíblicos de igualdad, oportunidad y gracia para todas las criaturas. En este entorno surge Martín Lutero y genera un punto de inflexión en la Historia por su visión del texto bíblico. La aproximación que realiza de la Escritura altera completamente la Teología y, por ende, su expresión en la vida cotidiana. Nos hallamos ante una vuelta a los valores transcendentes que incrementan a la persona como tal. Como observa Juan Belda (2010, p. 152):

Su deseo de profundizar en el conocimiento de la Biblia se funda en que la Palabra de Dios se le aparece como encadenada (oscurecida) por la Teología Escolástica y por la Autoridad Eclesiástica. De ahí que sus estudios escriturísticos le lleven no solo a una labor de investigación de los textos bíblicos, sino al cambio de toda la Teología y aun de la Iglesia misma.

Para empezar, Lutero reduce las fuentes de la Teología a la Sola Scriptura, rechazando la Tradición divino-apostólica. Igualmente rechaza el Magisterio eclesiástico como fuente interpretativa de la Revelación, quedándose solo con el juicio personal: Libre examen, para determinar el sentido de la Palabra de Dios. Todo ello supone una actitud reduccionista del método teológico tradicional (Belda, 2010).

En una breve comparación (véase Tabla I) podemos observar cuán relevante es su aporte y cómo varía considerablemente la gestión de paradigmas. La disponibilidad de la Escritura se incrementa sustancialmente. El invento y empleo de la imprenta, unido a la traducción de la Biblia a las lenguas vernáculas presenta un panorama de accesibilidad bien diferente al período anterior. La propuesta de Lutero de que exista una lectura sin "intermediarios" saca la religión de su formato gregario y lo sitúa en el espacio de lo individual. La variedad de traducciones de la Biblia deviene en un verdadero acercamiento comunicacional y en el resquebrajamiento progresivo de la estructura ternaria medieval. En palabras de Rentería (citado por León y Salvador Mora, 2006, p. 102):

El mayor aporte de la Reforma no es la separación entre los poderes político y religioso sino la libertad de conciencia. Lutero es el iniciador de la Reforma, pero lo que realmente inicia con Lutero es una guerra de libros, que tiene 
como finalidad la conquista de la libertad de conciencia: la emancipación del hombre de sus tutores medievales. En 1517 "Martín Lutero clava sus tesis en las puertas de la Catedral de Wittenberg, tales tesis estaban impresas en una traducción alemana y en el término de 15 días habían sido vistas en todo el país". En los años siguientes se publicarán más de 400 ediciones de sus traducciones bíblicas. Lutero fue excomulgado en 1520 por el Papa León $X$, sus libros fueron prohibidos, pero nadie podía detener ya esta contienda. Tal fue el pánico que desencadenó en los príncipes católicos que Francisco I, rey de Francia, "prohibió en 1535 la impresión de cualquier libro en su reino. ¡Bajo pena de la horca!" La guerra entre católicos y protestantes se desplazaba al campo de las letras, era una batalla por la conquista de la conciencia de los hombres y al mismo tiempo de la conquista de la libertad de conciencia.

El valor que le otorga al canon primigenio (canon hebreo) y su asociación con el principio de Sola Scriptura se asemeja a otros puntos de inflexión generados en su momento por Jerónimo de Estridón o por los caraítas. Es una vuelta a la lectura de la Escritura en su sentido plano sin la interferencia de auctoritas. El ejercicio de la hermenéutica en Lutero potencia dos componentes esenciales para una mejor comprensión de la Escritura: el método histórico-gramatical y la individualidad. El acercamiento personal a la Biblia fortalece la identidad religiosa y eclesiástica. La hermenéutica históricogramatical (heredera de tradiciones judías y antioquenas) se ve fortalecida por los estudios de los humanistas, especialmente Erasmo, que aportan método al análisis de los materiales en hebreo, arameo y, concretamente, en griego. La Palabra vuelve a ser, nuevamente, "verbo", motor generador de sentidos y acciones.

La Biblia cambia de adjetivación, pasa de ser "sagrada" a ser "santa". No nos hallamos ante un objeto mágico, un tótem per se, sino ante un elemento de santificación, un instrumento per relatio. Esa percepción del material bíblico fortalece la comprensión aportando al vocablo "fe" una dimensión mucho más concreta no solo en el plano salvífico sino en la comprensión de la cotidianeidad religiosa. La "fe" también es la cosmovisión del reformado y la misma cultura de este. Los versículos bíblicos forman parte del adoctrinamiento y de las enseñanzas de los oficios, de los eventos comunitarios y de la regulación de lo doméstico, de la más profunda teología a la más común praxis. Ni qué decir, por tanto, que la autoridad que se le confiere a la Biblia es normativa. Es Palabra que debe generar transformación y acción. 
Hay, sin embargo, un factor que se desdibuja en las propuestas de Lutero, es la preeminencia neotestamentaria sobre los materiales veterotestamentarios. Su concepto de inspiración, inducido por el énfasis de la justificación por la fe, le aleja de una comprensión de Tota Scriptura.

Uno de los puntales de esta inflexión se debe a las traducciones de los textos bíblicos. Afirman Delisle y Voodsworth (2005, pp. 39-42):

La calidad lingüística de la Biblia de Lutero obedece a la aplicación de un cierto número de principios de traducción. Primero que todo, Lutero predicaba el retorno de las lenguas originales de la Biblia, el hebreo para el Antiguo Testamento y el griego para el Nuevo Testamento, sin por ello desechar por completo la Vulgata... También le daba mucha importancia al medio cultural de los destinatarios de una traducción. Al traducir Las Sagradas Escrituras se esforzaba por darles un giro típicamente alemán, modificando el texto para adaptarlo a la mentalidad y el espíritu de la gente de su tiempo... Lutero afirmó también haber empleado un lenguaje simple para que sus traducciones fueran fáciles de entender. Trató de alcanzar un justo equilibrio entre el registro formal y el familiar, entre la lengua litúrgica y la cotidiana. En su epístola (Sendbrief) afirmó que se debería hablar alemán como "las personas en la plaza del mercado"... Pero su aporte más importante se sitúa en el plano estilístico. Claridad, facilidad de comprensión, simplicidad y vigor son las grandes cualidades del estilo de sus traducciones, cualidades que aun en nuestros días sirven de modelos de escritura. El mismo Lutero dijo de su estilo que "tocando cada uno de los cinco sentidos, penetra en el corazón y lo hace vibrar" (das also dringe und klinge ynns Hertz, durch alle Sinne).

Debemos a estos factores un período de sentido en la humanidad, una época de fortalecimiento de los valores porque la Escritura fue situada en una plataforma de influencia.

Tabla 1

\begin{tabular}{|c|c|c|}
\hline Escritura & Baja Edad Media & Reforma \\
\hline Disponibilidad & $\begin{array}{c}\text { Escasa (la Biblia es un texto } \\
\text { minoritario y de difícil acceso) }\end{array}$ & $\begin{array}{c}\text { Creciente (el invento de la } \\
\text { imprenta y la traducción a } \\
\text { las lenguas vernáculas la } \\
\text { convierten en más accesible) }\end{array}$ \\
\hline Variedad & Un solo texto en latín & $\begin{array}{c}\text { Una traducción oficial a la } \\
\text { lengua vernácula }\end{array}$ \\
\hline
\end{tabular}




\begin{tabular}{|c|c|c|}
\hline Configuración & $\begin{array}{l}\text { Canon ampliado (canónicos y } \\
\text { deuterocanónicos) }\end{array}$ & Sola Scriptura (canon hebreo) \\
\hline $\begin{array}{c}\text { Aproximación } \\
\text { interpretativa }\end{array}$ & Hermenéutica alegórica & $\begin{array}{l}\text { Hermenéutica histórico- } \\
\text { gramatical (doctrinal- } \\
\text { apologética) }\end{array}$ \\
\hline Relevancia & Sagrada Biblia (texto mágico) & Santa Biblia (texto inspirado) \\
\hline Eje de acción & Simbología & Fe \\
\hline Autoridad & Compartida (con el Magisterio) & $\begin{array}{c}\text { Normativa } \\
\text { y Nuevo Testamento amplificado }\end{array}$ \\
\hline $\begin{array}{c}\text { Comprensión de la } \\
\text { división }\end{array}$ & Antiguo y Nuevo Testamento & Traducciones literales \\
\hline Traducción & Traducción al latín liturgizada & \multicolumn{2}{|c|}{} \\
\hline
\end{tabular}

Fuente propia

\section{De la Alta a la Baja Edad Moderna}

La visión de Touraine (1997, pp. 159-192.) de la evolución social de los últimos siglos es de notable claridad. Sostiene que con la Ilustración surge lo que denomina la "Alta Edad Moderna". La identifica como un período que gira en torno a un principio de orden y desarrollo de la mentalidad científica. La Revolución Industrial propone nuevos matices a la Modernidad (la llama "Media Edad Moderna") que se identifican con la asociación de la industrialización y la configuración del concepto de nación. Hoy día, se vive en la "Baja Edad Moderna". Tal y como él lo plantea, dispensa "una posición a la vez central y débil del sujeto entre los dos universos opuestos de los mercados y de las comunidades". ${ }^{2}$ Mallimaci $(2008$, p. 80 ) describe desde un horizonte similar este período que estamos viviendo:

Al comienzo del siglo XXI, fruto de la globalización financiera, el derrumbe del bloque socialista, la disminución de los estados nacionales (mundialización) y el avance de la mercantilización en el planeta, hay autores que hablan de una "aceleración" de la modernidad capitalista. Hipermodernidad o modernidad avanzada o individualidad en una sociedad de riesgo personal y mundial, "con categorías zombies, que han muerto y siguen vivas" donde hay "una nueva concepción del tiempo, el riesgo y las oportunidades" junto

\footnotetext{
${ }^{2}$ Véase el capítulo "Haute, moyenne et basse modernités" de Touraine, A. (1997). Pourrons-nous vivre ensemble? Egaux et différents. Paris: Fayard, pp. 159-192. Touraine, A. (1969). La sociedad post-industrial. Barcelona: Ariel; Touraine, A. (2013). La fin des sociétés. Paris: Éd. du Seuil; Touraine, A., Bixio, A. (2000). Crítica de la modernidad. México: Fondo de Cultura Económica; Touraine, A., Khosrokhavar, F., y Gómez, V. (2002). A la búsqueda de sí mismo: diálogo sobre el sujeto. Barcelona: Paidós; Touraine, A., Mercado, T. (1978). Las sociedades dependientes. México: Siglo Veintiuno Editores; Touraine, A. (1969). Sociología de la acción. Barcelona: Ariel.
} 
a modernidades múltiples y plurales y propuestas de otra modernización como la planteada por el Forum Social Mundial son diferentes conceptos que tratan de dar cuenta de una pluralidad en lo que hoy vivimos.

La amenaza y cercanía al desempleo, a la pobreza, al riesgo y a la incertidumbre en el futuro produce una angustia generalizada a nivel planetario. Si "ayer" esto llevaba a crear organizaciones, hoy la individualidad acelerada produce la disolución de los vínculos entre las elecciones individuales y los proyectos y acciones colectivas (Mallimaci, 2008).

¿Cómo hemos llegado a otra etapa sumergente de valores desgastados? Como respuesta, propongo, nuevamente, una lectura de la sociedad desde su relación con la Biblia. Contrastaremos los elementos identificativos de la Alta Edad Moderna (AEM) con los de la Baja Edad Moderna (BEM) para detectar la evolución que se ha realizado en estos siglos (véase Tabla 2).

La AEM generaliza el acceso de los textos bíblicos desarrollando un fuerte interés por el estudio de los manuscritos, sus relaciones y variantes (Crítica Textual). Tal dinámica se incrementa exponencialmente, generando en la BEM un exceso de materiales y una notable infoxicación.

Esta es una de las paradojas culturales más representativas de nuestra época: disponemos de los recursos y medios para la accesibilidad a la información, pero la limitada capacidad del proceso de la mente humana provoca que el umbral de comprensibilidad de los acontecimientos se vea sobrepasado por la excesiva cantidad de información que recibimos. Por ello, distintos autores afirman que la sociedad de la información no significa necesariamente una sociedad de mayor conocimiento. Una cosa son los datos y otra bien distinta la capacidad de interpretarlos, darles sentido y significado útil para ciertos propósitos (Fundación Telefónica, 2012, p. 22).

La AEM potenció las versiones nacionales frente a la BEM que multiplica, obviamente por intereses editoriales, las versiones más variadas. El efecto de no identificar una versión con una denominación o una identificación cultural que podría, a primera vista, parecer positivo (se acaba aquella calificación de Biblia "católica" o "protestante") termina por afectar el lenguaje común (en muchas ocasiones liturgizado) de las comunidades de creyentes. Además, tal cantidad de versiones provoca en los sectores más radicales una vuelta a textos antiguos de corte arcaizante o de difícil comprensión.

Si bien la desfragmentación del canon era preocupante en la AEM porque creaba cierto descrédito de los textos bíblicos, la descanonización de 
la BEM es mucho más alarmante. La inclusión en la mesa de interpretaciones de textos acanónicos, pseudoepigráficos o esotéricos provoca, sin lugar a dudas, una superficialidad pasmosa en la aproximación hermenéutica. No hay canon porque no hay límites.

La hermenéutica histórico-crítica de la AEM había aportado método a las ciencias bíblicas pero estableció axiomas positivistas que se cuestionan desde lo metodológico (Popper, Lakatos, Kuhn, Feyerabend) hasta lo lingüístico (James Barr). Parecía que la hermenéutica canónica (Brevard Childs) iba a aportar alguna vía de escape pero fue fugaz y la BEM se sumió en el laberinto de las aproximaciones sincrónicas. Nos hallamos, en este momento, ante una hermenéutica descriptiva y emocional que avanza entre el Análisis del Discurso y la Narratología. El relato bíblico parece abandonar su naturaleza de "history" y profundizar en el formato de "story".

La Biblia no es un texto inspirado, apenas si supera los niveles de literatura, en la AEM, como mucho el producto de grandes genios de la espiritualidad. En la BEM es simplemente un texto inspirante, se adapta a las diferentes realidades en un ejercicio de contextualización. Los receptores redefinen el proceso de transformación generando, en ocasiones, disonancias insoslayables.

El eje de acción de la AEM era la Historia, se hallaba en la diacronía y en sus artefactos (Arqueología, Crítica Literaria, Crítica Textual, Religiones Comparadas, etc.) la explicación de la evolución del pensamiento. Tal proceso colocaba al lector en el clímax del conocimiento. La BEM, en su radical actividad relativizante, pone el eje en la Subjetividad y en la Emoción. El contenido no afecta tanto como el continente, la experiencia espiritual personal suple la búsqueda de lo verdadero.

Los artefactos de este período son la opinión y el gusto. Abandonado el metarrelato solo queda el microrrelato individualizante y atomizador.

Para la AEM la Biblia no era autoridad, para la BEM la Biblia representa una autoridad desgastada y descolorida. Desgastada porque responde a la imagen de las iglesias con sus escándalos y fraudes. Descolorida porque se la reviste del siena de lo añejo y se la considera superada. Es una fotografía de familia que despierta extrañeza por las costumbres de otros tiempos.

La AEM concebía los textos bíblicos desde dos plataformas bien diferenciadas: La Biblia judía y la Biblia cristiana. Uno de los factores puede estribar en el hecho de que numerosos teólogos de este período se adherían a supuestos antisemitas. La BEM prefiere una expresión taxonómica más neutra y tolerante: Primer y Segundo Testamento. 
Si bien la AEM consideró el género literario para los procesos de traducción, el resultado solía ser bastante literal, desmitificador y academizante. La BEM fluye en las premisas de la traducción dinámica. Pero, ¿cuáles son los límites de ese dinamismo? López García (1991, pp. 92,93) nos ayuda a reflexionar sobre este asunto:

En realidad, el principio de la equivalencia dinámica es un último recurso, al que hay que acudir cuando ha fallado todo otro intento de traducir el término que figura en el texto de la LD [Lengua Destino]. Es un principio que, mal aplicado, puede conducir a resultados análogos a los del literalismo. La equivalencia dinámica deja en manos del traductor una responsabilidad que a la larga lo conducirá a situaciones sin salida o a una labor en la que ese principio de equivalencia dominará todos los aspectos de la traducción. Si lo único que se puede pedir a un traductor es que sea consecuente con sus principios, ¿qué clase de traducción de la Biblia se obtendrá si hay que hallar un equivalente dinámico para las instituciones sociales, formas de vida, términos del dominio afectivo, flora y fauna, campo simbólico, etc.?... La traducción funcional aplicada sin unos criterios de corrección puede conducirnos a excesos tan indeseados como los de la traducción palabra por palabra.

Tabla 2

\begin{tabular}{|c|c|c|}
\hline Escritura & Alta Edad Moderna & $\begin{array}{l}\text { Baja Edad Moderna } \\
\text { (Modernidad líquida o Posmodernidad) }\end{array}$ \\
\hline Disponibilidad & Acceso generalizado & Exceso (infoxicación) \\
\hline Variedad & Versiones nacionales & Versiones múltiples \\
\hline Configuración & Canon fragmentado & $\begin{array}{l}\text { Descanonización (inclusión de textos aca- } \\
\text { nónicos, pseudoepigráficos y esotéricos) }\end{array}$ \\
\hline $\begin{array}{l}\text { Aproximación } \\
\text { interpretativa }\end{array}$ & $\begin{array}{l}\text { Hermenéutica histórico- } \\
\text { crítica }\end{array}$ & $\begin{array}{l}\text { Hermenéutica sincrónica (descriptiva y } \\
\text { emocional) }\end{array}$ \\
\hline Relevancia & Biblia (texto no inspirado) & Nueva Biblia (texto inspirante) \\
\hline Eje de acción & Historia & Emoción \\
\hline Autoridad & No autoridad & Autoridad desgastada \\
\hline $\begin{array}{c}\text { Comprensión de la } \\
\text { división }\end{array}$ & $\begin{array}{l}\text { Biblia judía y Biblia cris- } \\
\text { tiana }\end{array}$ & Primer Testamento y Segundo Testamento \\
\hline Traducción & $\begin{array}{c}\text { Traducción desde el géne- } \\
\text { ro literario }\end{array}$ & Traducción dinámica \\
\hline
\end{tabular}

Fuente propia 
La situación en la BEM no es tan distinta de la vivida en la Baja Edad Media. Este mundo sumergente se ha instalado en la relatividad, en la estética con sus símbolos, en la ambigüedad y confusión. Como resultado, la persona se torna en homo consumericus. Como sugiere Lipovetsky (2013), hay ciertos rasgos en el hombre de la actualidad que se aproximan al turboconsumidor: participación provisional, incorporación comunitaria libre, comportamientos a la carta, primacía del mayor bienestar subjetivo y de la experiencia emocional. Es la disolución de lo religioso en el consumo por la falta de referentes o porque aquellos que tenemos se nos presentan como un supermercado del sentido donde se toma o deja lo que apetece.

¿Cómo posicionarnos como creyentes e intelectuales? ¿Cómo aportar un punto de inflexión que proponga modelos de plenitud a personas en lugar de ofertas de consumo? Quizá debiéramos realizar un ejercicio de coherencia y de transcendencia.

\section{El prescriptor del Metarrelato y el Hipertexto}

El intelectual cristiano no puede permitir que la Biblia deje de ser el marco esencial del Metarrelato. Apartado de premisas fundamentalistas o reductoras tiene la tarea de aportar coherencia al ser humano a través de la cosmovisión que propone el texto bíblico. Su figura no es la de un simple descriptor sino que tiene el desafío de prescribir.

La función de los académicos creyentes se ha autolimitado a espacios que surfean en el mensaje bíblico, situándose en las zonas de seguridad de la descripción:

1. Método. La posmodernidad ve imposible la objetividad y enfoca el significado de cualquier texto en el lector. Influidos por estos conceptos, los descriptores cristianos circulan por la ambigüedad de las múltiples opiniones. Se ha trocado el "así dice Yhwh" por el "yo opino que".

2. Subjetividad. Colocar el eje de cualquier sentido en la subjetividad es crear una fragmentación del Todo que anula ese mismo sentido. Se cambia a Dios y la Verdad por infinidad de diosecillos desorientados con verdades locales. El descriptor pasa a ser un simple notario de la multiplicidad de pareceres.

3. Relato. La narración no deja de ser "story" y el descriptor un cuentacuentos (storyteller) que deambula entre la ficción y el mito frente a una comunidad de creyentes que sospecha, consciente o inconscientemente, 
de la realidad del texto. La Biblia es un registro de composiciones más o menos fabuladas que apenas si superan la destreza de un esbozo literario.

4. Tolerancia. El anhelo de agradar se confunde con el ejercicio de la tolerancia. El descriptor simplemente describe porque, con ello, no sobrepasa el espacio de la privacidad. El temor a la intromisión maniata al descriptor tendiendo a confundir el "quedar bien" con "hacerlo bien".

5. Visualización. La expresión natural del descriptor es la verbalización de la visualización. La Biblia que agrada es una Biblia visualizada, narrada e ilustrada. Hay cierto misticismo en la contemplación de las imágenes, escenas o planos de las narraciones bíblicas que se presentan en hiato con la realidad cotidiana.

6. Reconocimiento. El objetivo del descriptor, sobre todo en los productos académicos, no supera el reconocimiento de las formas literarias, las estructuras teológicas, el listado de campos semánticos, las múltiples opiniones de las autoridades. Tras el "collage" de argumentos o pensamiento apenas si se intuye una relación con la cotidianeidad.

Si existe consistencia en el discurso del intelectual cristiano, si se tienen las agallas de seguir manteniendo que la Escritura es Palabra de Dios, no podemos limitarnos a la función de descriptores. Es un simple ejercicio de coherencia.

La Biblia es el Hipertexto por excelencia. No hay otro libro que pueda establecer links como este. Algunos se atreverían a sostener que es el hipotexto de la cultura occidental pero llega mucho más allá. Supera la bidimensionalidad significante-significado, letra-idea, emisor-receptor para alcanzar el sentido de la persona con el tiempo (explica el ayer, significa el hoy y clarifica el mañana), con el espacio (completa el aquí y acerca el allá) con el ser (posiciona el yo, descubre al otro, revela a Él). La Biblia es el Hipertexto porque genera transcendencia.

Si esa es la naturaleza de la Biblia, si vivimos en un mundo sumergente, no tenemos otra opción que ser prescriptores. Hemos, por tanto, de revisar nuestras funciones:

1. El Camino frente al método. La Biblia presenta con claridad que el método para un proceso de prescripción no responde a "qué" sino a "quién". Jesús es el camino, Jesús es el método. No consiste en un protocolo o en un listado de acciones, consiste en entender que la transcendencia surge y deviene en una persona. Esa persona, además, es el Cristo, lo que implica una participación de lo divino en el proceso de influencia y mejora. 
2. La verdad frente a la subjetividad. Si algo distingue el cristianismo neotestamentario del judaísmo tannaíta es su linealidad. El texto bíblico puede ser lineal porque hay certeza de que la verdad no es un ejercicio de aproximación sino la constatación por medio de la fe de que existe lo correcto y lo incorrecto. El intelectual cristiano, como prescriptor, busca la Verdad no para poseerla o instrumentalizarla sino para vivirla y ayudar a otros a vivirla también.

3. La vida frente al relato. Biblia no es una compilación de relatos sino una colección de experiencias. El texto se expresa literariamente pero refleja la vida. No se cuestiona la historicidad ni la narratividad pero se potencia la vida. El prescriptor detecta la grandeza de la experiencia humana ante la divina y la propone como ejemplo de vida. La Biblia vivida es agente de vitalización.

4. El respeto frente a la tolerancia. El fundamento de todo principio bíblico es el amor. El respeto surge de dicho fundamento y, como tal, es activo. El respeto empatiza hasta tal extremo que anhela y procura la mejora del otro. Hacer lo bueno y compartir lo bueno es imprescindible en la tarea del prescriptor. La intrusión se abandona por la complicidad, la imposición por la oferta, el dogmatismo por la relación.

5. La vivificación frente a la visualización. Hay que salir del escenario, incluso de las gradas del teatro religioso para acudir a las calles de la existencia. La Biblia no se puede quedar en los retablos, bajorrelieves o autos sacramentales de la posmodernidad. Debe ser más que un imaginario, debe incorporar cada resquicio de la vida. Es urgente abandonar este platonismo eclesiástico y teológico, tanto en sermones como en artículos, y vivificar el texto bíblico.

6. La transformación frente al reconocimiento. No es suficiente con reconocer la vida en la Biblia, hay que recomponer vidas con la Biblia. La transformación es uno de los objetivos más trascendentes de la Escritura. Debiera ser la prioridad en el ejercicio de la Teología y de la Praxis. Dios interviene en la historia para que el Metarrelato se convierta en nuestro relato, para que nos convirtamos ante el Relator de relatores y Prescriptor de prescriptores.

Nadie va a decir que la tarea sea fácil, ¿lo fue alguna vez? Me imagino a Lutero contemplando nuestro mundo sumergente y proponiendo con intensidad un punto de inflexión. Sugeriría, posiblemente, algunos cambios en nuestra relación con la Escritura (véase Tabla 3). Primero, una disponibilidad de la Biblia presente entre los creyentes y, a su vez, alejada 
de los intereses del mercado. Versiones del texto que estableciesen, además de contextualización, relaciones con la verdad del contenido y con las necesidades de los receptores. Una vuelta al canon primigenio porque hace falta un modelo y que sea original. Una hermenéutica histórico-lingüística que sea prescriptiva y sentimental (la emoción discurriendo a través de la razón). La Santa Biblia concebida como texto inspirado e inspirante, ese espacio donde la revelación se encuentra con la iluminación y la vida. Una vuelta a la "fe" como eje de acción, como motor espiritual y material. Un texto bíblico que impacte en la vida como guía de crecimiento, como autoridad que surge de un liderazgo que transforma. Una comprensión de la Biblia como plenitud de comunicación donde Sola Scriptura se hermana con Tota Scriptura. Un material que sea traducido de forma integral e integrante donde se realice un esfuerzo de transmisión de continentes y contenidos por igual.

Cambios, tengo la certeza, que nos acercarían a nuevas realidades. A una mirada de este mundo más cercana a Yhwh.

Tabla 3

\begin{tabular}{cc} 
Escritura & $\begin{array}{c}\text { El Hipertexto en un cristianismo coherente y } \\
\text { trnscendente }\end{array}$ \\
\hline Disponibilidad & Presente y liberada del mercado \\
\hline Variedad & Versiones relacionales \\
\hline Configuración & Canon primigenio \\
\hline Aproximación interpretativa & Hermenéutica histórico-lingüística (prescriptiva y \\
& sentimental) \\
\hline Relevancia & Santa Biblia (texto inspirado e inspirante) \\
\hline Eje de acción & Fe \\
\hline Autoridad & Autoridad de vida \\
\hline Comprensión de la división & Biblia \\
\hline Traducción & Traducción integral e integrante \\
\hline Fuente propia
\end{tabular}

Víctor M. Armenteros Cruz Universidad Adventista del Plata email: mizpahve@gmail.com

Recibido: 30 de diciembre de 2013 Aceptado: 31 de enero de 2014 


\section{Víctor M. Armenteros Cruz}

\section{Referencias}

Antúnez, J. (2001). Crónica de las ideas. En busca del rumbo perdido. Madrid: Encuentro. Belda, J. (2010). Historia de la Teología. Madrid: Palabra.

Carrasco, A., Rábade, M. (2008). Pecar en la Edad Media (coord). Madrid: Sílex Delisle, J., Voodsworth, J. (2005). Los traductores en la historia. Antioquía: Universidad de Antioquía. Fundación Telefónica (2012). Alfabetización digital y competencias informacionales. Madrid: Ariel. Grabbe, L. (2007). Ahab Agonistes: The Rise and Fall of the Omri Dynasty, (ed). Journal for the Study of the Old Testament Supplement series 421. Londres: T\&T Clark.

Le Goff, J. (2008). Una larga Edad Media. Barcelona: Paidós Ibérica.

Le Goff, J. (2004). Héros du Moyen Âge, le Saint et le Roi. Paris: Gallimard.

Le Goff, J. (1985). El nacimiento del purgatorio. Madrid: Taurus.

León y Ramírez, J., Mora, S. (2006). Ciudadanía, democracia y políticas públicas. (ed). México, D.F.: UNAM.

López García, D. (1991). Sobre la imposibilidad de la traducción. Cuenca: Ediciones de la Universidad de Castilla-La Mancha.

Lipovetsky, G. (2013). La felicidad paradójica: ensayo sobre la sociedad de hiperconsumo. Barcelona: Anagrama.

Mallimaci, F. (2008). Modernidad, religión y memoria. (coord). Buenos Aires: Colihue.

Touraine, A. (1997). Pourrons-nous vivre ensemble? Egaux et différents. Paris: Fayard.

Zizek, S. (2011). En defensa de causas perdidas. Madrid, Akal. 